Soil Use and Management (2003) 19, 119-126 DOI: 10.1079/SUM2002178

\title{
Soil salinity and its distribution determined by soil sampling and electromagnetic techniques
}

\author{
J. Herrero*, A.A. Ba \& R. Aragüés \\ Soils and Irrigation Dept., Laboratorio Asociado de Agronomía y Medioambiente (DGA-CSIC), 50080 Zaragoza, Spain. \\ *Corresponding author. Fax: +34 976716 145. E-mail: jhi@eead.csic.es
}

\begin{abstract}
Diagnosis of soil salinity and its spatial variability is required to establish control measures in irrigated agriculture. This article shows the usefulness of electromagnetic (EM) and soil sampling techniques to map salinity. We analysed the salinity of a 1-ha plot of surface-irrigated olive plantation in Aragon, NE Spain, by measuring the electrical conductivity of the saturation extract (ECe) of soil samples taken at 22 points, and by reading the Geonics EM38 sensor at 141 points in the horizontal (EMH) and vertical (EMV) dipole positions. EMH and EMV values had asymmetrical bimodal distributions, with most readings in the non-saline range and a sharp transition to relatively high readings. Most salinity profiles were uniform (i.e.
\end{abstract} $\mathrm{EMH}=\mathrm{EMV})$, except in areas with high salinity and concurrent shallow water tables, where the profiles were inverted as shown by EMH $>$ EMV, and by ECe being greater in shallow than in deeper layers. The regressions of ECe on EM readings predicted ECe with $\mathrm{R}^{2}>84 \%$ for the $0 \pm 100$ to $0 \pm 150 \mathrm{~cm}$ soil depths. We then produced salinity contour maps from the 141 ECe values estimated from the electromagnetic readings and the 22 measured values of ECe. Owing to the high soil sampling density, the maps were similar (i.e. mean surface-weighted ECe values between $3.9 \mathrm{dSm}^{-1}$ and $4.2 \mathrm{dSm}^{-1}$ ), although the electromagnetically estimated ECe improved the mapping of details. Whereas soil sampling is preferred for analysing the vertical distribution of soil salinity, the electromagnetic sensor is ideal for mapping the lateral variability of soil salinity.

Keywords: Soil salinity, electromagnetic sensor, olive trees, irrigation, Spain.

\section{INTRODUCTION}

In the central valley of the river Ebro, one of the most arid areas in Europe, irrigation is required for protable agricultural production. However, the aridity, coupled with the saliferous Miocenic strata that are present in large areas of the central Ebro valley, has 
been further compounded by improper soil and irrigation management, resulting in the development of about 250000 ha of salt-affected soils (Herrero \& Aragüés 1988). This salinity poses a severe limit to agriculture and a threat to its sustainability; so the need for identi ${ }^{\circledR}$ cation, monitoring and control of salinity is increasing in the central Ebro valley, as well as in many similar arid and semiarid irrigated areas of the world. Moreover, irrigated agriculture in the Ebro valley is adapting to changes in markets as well as new agricultural policies imposed by the European Union. The plot studied in this work is an example of this adaptation, where olive trees are being grown in a salinesodic soil, which is an unusual environment for this crop. This soil has a complex salinity distribution, and an in-depth knowledge of the patterns will help to design adequate monitoring and agricultural practices.

The electromagnetic measurement of soil salinity is a non-destructive technique based on the emission of a primary electromagnetic wave and the concurrent measurement of a soil-induced secondary wave whose intensity depends, among other variables, on the electrical conductivity of the bulk soil (ECa). The portable electromagnetic sensor EM38 (Geonics Ltd, Canada) is suitable for diagnostic and agronomic purposes, since around $80 \%$ of the ECa response is due to the $0-100 \mathrm{~cm}$ (horizontal dipole disposition) and 0-200 cm (vertical dipole disposition) soil depths. The EM38 has been used to appraise soil salinity in many studies during the last 20 years (Rhoades et al. 1999). The EM38 has been widely used in the central Ebro valley to map soil salinity at the irrigation district level (Herrero \& Bercero 1991; Tedeschi et al. 2001) and at the plot scale (AraguÈeÂs 1987; López-Bruna \& Herrero 1996), to monitor soil salinity over time (Lesch et al. 1998) and to relate crop yield responses to salinity under natural (Bercero \& AraguÈeÂs 1996) and artifcial feld conditions (AraguÈeÂs et al. 1992, 1999).

In recent work, $\mathrm{Ba}$ (2001) used the EM38 in the central Ebro valley to appraise soil salinity in areas, ranging from experimental plots to medium-sized irrigation districts, including salinity monitoring over time, to evaluate the advantages and limitations of this technique. The results were generally consistent and helpful. It was found that the instrument should be calibrated for each soil and date of measurement because of the influence of soil type, soil temperature, soil moisture and the vertical distribution of soil salinity on the EM38 readings. Although the calibration process requires some soil sampling and analysis, the field and laboratory workload is much less than for a traditional soil survey. 
The objectives of the present study were (i) to describe the vertical and lateral distribution of soil salinity in a plot that has undergone several changes in crops and irrigation systems, and (ii) to evaluate the usefulness of the EM38 to map soil salinity, as compared to conventional soil sampling methods.

\section{MATERIALS AND METHODS}

\section{Location and description of the plot under study}

The plot is located in the middle Ebro valley, close to the town of Callén in the Flumen irrigation district (Figure 1). The climate is characterized by mean annual values of $15.3^{\circ} \mathrm{C}, 434 \mathrm{~mm}$ precipitation and $1188 \mathrm{~mm}$ ET0, based on records at the Almuniente weather station, located $10 \mathrm{~km}$ from the plot. The soil moisture regime is on the border of the xeric and the aridic regimes defined by Soil Survey Staff (1999). The irrigation water is of excellent quality for crop production $\left(\mathrm{EC}<0.4 \mathrm{dS} \mathrm{m}^{-1}, \mathrm{SAR}<1\right)$, although its low EC may cause structural (i.e. clay dispersion) and water penetration problems in these illitic soils. Inadequate water and soil management, the high evaporative demand and the saliferous underlying rock strata, all contribute to explain the widespread occurrence of saline-sodic soils in the Flumen-Monegros district (Vizcayno et al. 1995; Nogués et al. 2000).

The plot is part of the 9-ha Agro-Callén farm, previously irrigated with solid-set sprinklers and currently flood-irrigated, using the concrete ditches built when this area was first irrigated. The sprinkler system was installed in 1980, and at the same time gravel was applied in those areas prone to water ponding. Forage crops were grown initially, but the rise in soil salinity and the low crop prices led the owner to substitute them with rice. The plots were levelled, the soil puddled and flooded, and rice was cropped from 1992 to 1996. In the spring of 1997, the land was graded with a gentle slope to avoid water logging and planted with olive trees (Olea europaea L. cv. arbequina). Plot No. 6 (250340 m) was selected for study because of the salinity gradient along it, as evidenced by salt efflorescence, water logging, the presence of halophytes and the variable growth of the olive trees. The trees were well developed on the southern half of the plot with a transition zone of stunted trees leading to dead trees in the remaining $80-100 \mathrm{~m}$ of the northern part of the plot. This salinity gradient was confirmed by shallow soil samples taken from the three areas in February 1999. The ECe (saturation extract EC) values were $1.7 \mathrm{dS} \mathrm{m}^{-1}$ in the non-saline area, $9.5 \mathrm{dS} \mathrm{m}^{-1}$ in the transition area, and $15.6 \mathrm{dS} \mathrm{m}^{-1}$ in the saline area.

\section{Field measurements}


The EM38 readings (16 June 1999) were made every $10 \mathrm{~m}$ along five transects parallel to the nine tree lines. The transects formed an orthogonal grid whose cells measured $10 \mathrm{~m} \times 8 \mathrm{~m}$ giving a total of 141 points for the EM38 readings in the horizontal $\left(\mathrm{EM}_{\mathrm{H}}\right)$ and vertical $\left(\mathrm{EM}_{\mathrm{V}}\right)$ dipole positions. In addition, soil temperatures were measured at depths of $20 \mathrm{~cm}$ and $40 \mathrm{~cm}$ with a digital soil thermometer in order to convert the EM38 readings to a reference temperature of $25^{\circ} \mathrm{C}$. These readings were performed several days after an irrigation (i.e., at relatively high soil water contents), as soon as the field was trafficable.

Twenty-two of the 141 points, covering both the entire studied area and the full range of EM38 readings, were selected for soil sampling and EM38 calibration purposes. Within 4 hours of EM38 runs, six soil samples were taken in each of the 22 sampling points at 25-cm depth increments using an Edelman auger. Soil moisture increased with depth at all the sampling points. The 132 samples were air-dried, ground and sieved $(<2 \mathrm{~mm})$. ECe was measured in the soil saturation extract (United States Salinity Laboratory Staff 1954), and the average ECe values were calculated for each of the six soil depths $(0-25,0-50,0-75,0-100,0-125$ and $0-150 \mathrm{~cm})$ for EM38 calibration.

The trunk diameter of 341 olive trees, numbered 1-70 of rows 5-9, were measured in September 1999 and 2000. The difference in diameter was plotted against the average ECa measured on both dates.

\section{Data analysis}

Both EM38 readings and ECe values were submitted to exploratory data analysis by histograms, measures of central tendency (mean, median and quartiles), and dispersion (standard deviation, variance, and coefficient of variation).

\section{Calibration of EM38}

The EM38 readings were calibrated against the ECe to obtain simple and multiple linear regressions of $\mathrm{ECe}$ on $\mathrm{EM}_{\mathrm{H}}$ and on $\mathrm{EM}_{\mathrm{V}}$. The simple linear regressions were computed for the six increasing sample depths, irrespective of the distribution of their variables.

In addition, multiple linear regressions were also obtained using the logtransformed variables to give a gaussian distribution (Isaaks \& Srivastava 1989). Since the co-linearity between $\mathrm{EM}_{\mathrm{H}}$ and $\mathrm{EM}_{\mathrm{V}}$ is a constraint when computing the regressions of $\mathrm{ECe}$ on $\mathrm{EM}_{\mathrm{H}}$ and $\mathrm{EM}_{\mathrm{V}}$, we reduced it by taking the difference between the logtransformed $\mathrm{EM}_{\mathrm{H}}$ and $\mathrm{EM}_{\mathrm{V}}$ values as the second independent variable instead of $\mathrm{EM}_{\mathrm{V}}$ 
(Lesch et al. 1992). We also explored the fourth root transformation of $\mathrm{ECe}, \mathrm{EM}_{\mathrm{H}}$ and $\mathrm{EM}_{\mathrm{V}}$, as used by Rhoades et al. (1989) for normalization purposes.

In order to choose the best equations for EM38 calibration, all the above regressions were evaluated through the statistical significance of their coefficients of determination and by comparing their slopes and intercepts, and their standard errors. Spatial variability of soil salinity

The vertical distribution of soil salinity was studied by examining the $0-150 \mathrm{~cm}$ ECe profiles obtained at each of the 22 sample points. We considered that a profile was inverted when the ECe of the surface layers was greater than the ECe of the deeper layers. This is an important consideration, since inverted profiles are usually developed in the presence of shallow water tables. The horizontal distribution of soil salinity was studied by examining the ECe contour lines obtained through interpolation by kriging using the Surfer program. The contour maps were obtained for the $0-100 \mathrm{~cm}$ and the 0 $150 \mathrm{~cm}$ soil profiles from the 22 ECe measured values and from these measured values plus the 119 ECe values estimated from the EM38 readings.

\section{RESULTS AND DISCUSSION}

Exploratory data analysis and salinity profiles

Frequency histograms of $\mathrm{EM}_{\mathrm{H}}$ and $\mathrm{EM}_{\mathrm{V}}(141 \mathrm{EM} 38$ points and $132 \mathrm{ECe}$ values measured at the 22 soil sampling points) indicated a bimodal distribution (Figure 2), with most readings below $1.0 \mathrm{dS} \mathrm{m}^{-1}$ and above $1.5 \mathrm{dS} \mathrm{m}^{-1}$. This suggests a narrow transition zone between relatively low and relatively high soil salinity values. However, the distributions were asymmetrical in that most EM38 readings were low (i.e., a large proportion of the plot is non-saline).

The distribution of $\mathrm{EM}_{\mathrm{V}}$ was slightly more uniform than the distribution of $\mathrm{EM}_{\mathrm{H}}$ (Figure 2), suggesting that the variability of the apparent EC was smaller for the deeper layers. This result agrees with the presence of a shallow water table at depths above 1.5 $\mathrm{m}$ in the first $100 \mathrm{~m}$ of the plot, which smoothed somewhat the $\mathrm{EM}_{\mathrm{V}}$ readings due to over-saturation of the deeper layers in contact with the water table. The EM38 histograms obtained for the 141 EM38 points and for the 22 points selected for soil sampling were similar (Figure 2, and median and mean values in Table 1), indicating that these sampling points properly represented the salinity distribution of the entire plot. This is also evidenced by the mean and the median $\mathrm{EM}_{\mathrm{H}}$ and $\mathrm{EM}_{\mathrm{V}}$ values 
computed for the 141 reading points and the 22 sampling points (Table 1), which were not significantly different $(\mathrm{P}>0.05)$.

Table 1 displays relevant statistics of $\mathrm{EM}_{\mathrm{H}}$ and $\mathrm{EM}_{\mathrm{V}}$, and of the average $0-100 \mathrm{~cm}$ and $0-150 \mathrm{~cm}$ ECe profiles at the 22 sampling points. Both ECe profiles had similar statistics indicating that, as shown later, the vertical variability of salinity in the deeper horizons was low. The substantial differences observed between the mean and the median is in agreement with the histograms shown in Figure 2. The coefficients of variation of $\mathrm{EM}_{\mathrm{H}}, \mathrm{EM}_{\mathrm{V}}$ and $\mathrm{ECe}$ were very high (in particular for $\mathrm{ECe}$ ) confirming the large variability in the lateral soil salinity.

The $\mathrm{EM}_{\mathrm{H}}$ and the $\mathrm{EM}_{\mathrm{V}}$ readings were linearly correlated $(\mathrm{P}<0.0001)$, although some dispersion was evident for the larger EM38 values (Figure 3). Both $\mathrm{EM}_{\mathrm{H}}$ and $\mathrm{EM}_{\mathrm{V}}$ readings were similar (i.e., slopes close to one, and intercepts close to zero), although for values above $2 \mathrm{dS} \mathrm{m}^{-1}$ the $\mathrm{EM}_{\mathrm{H}}$ readings were somewhat higher than the $\mathrm{EM}_{\mathrm{V}}$ readings. This result suggests that most salinity profiles were uniform (i.e., $\mathrm{EM}_{\mathrm{H}}=$ $E M_{V}$ ), except at points with high salinity values where the profiles were inverted (i.e., $\left.\mathrm{EM}_{\mathrm{H}}>\mathrm{EM}_{\mathrm{V}}\right)$

This conclusion is supported by the ECe salinity profiles obtained at the 22 sampling points, which show that they were quite uniform for ECe values below $5 \mathrm{dS} \mathrm{m}^{-1}$, but were more variable and had in general an inverse configuration for ECe values above 10 $\mathrm{dS} \mathrm{m}^{-1}$ (Figure 4). Thus, the most inverted profiles occurred at points A2, A5, B6, F4 and F5, located in the northern $60 \mathrm{~m}$ of the plot, which is the most saline area with the highest water table. The water table depth in this area varied between $0.6 \mathrm{~m}$ and $0.8 \mathrm{~m}$ during the irrigation season, against values of $1.5 \mathrm{~m}$ or deeper in the rest of the plot. These inverted profiles were therefore the consequence of the upward capillary flow of water from the shallow water table and the subsequent evapo-concentration of water and salts at the soil surface. The use of the EM38 to identify shallow water tables should be further pursued, since this application could be of interest for diagnostic and salinity control purposes.

\section{Analysis of the EM38 - ECe calibration equations}

The simple linear regressions obtained between the various average ECe depths (i.e., from $0-25$ to $0-150 \mathrm{~cm}$ soil depths) and the $\mathrm{EM}_{\mathrm{H}}$ and $\mathrm{EM}_{\mathrm{V}}$ values measured at the 22 soil sampling points were highly significant (i.e., all $\mathrm{R}^{2}$ were significant at $\mathrm{P}<$ $0.0001)$, with intercept values not significantly different from zero $(\mathrm{P}>0.05)$ and slopes significantly different from zero $(\mathrm{P}<0.001)$ (Table 2, equations 1 to 12$)$. With 
increasing soil depth $\mathrm{R}^{2}$ values increased, especially for the vertical dipole configuration $\left(E M_{V}\right)$. On the other hand, the slope values decreased with increasing soil depths, from values of around 7.2 for the $0-25 \mathrm{~cm}$ soil depth (equations 1 and 2 ) to values of around 5.3 for the $0-150 \mathrm{~cm}$ soil depth (equations 11 and 12, Table 2). These decreases in slopes are attributed to the greater soil water content of the deeper layers in the presence of a relatively shallow water table.

The absence of large residuals for the simple linear regressions leads us to conclude that the calibration equations allow accurate prediction of ECe from EM38 values, especially for soil depths of $100 \mathrm{~cm}$ or greater (i.e., $\mathrm{R}^{2} \geq 84 \%$ ).

The multiple linear regressions of $\mathrm{ECe}$ on $\mathrm{EM}_{\mathrm{H}}$ and $\mathrm{EM}_{\mathrm{V}}$ were calculated for the six consecutive soil depths, and the log-transformed variables were also used to compute the multiple linear regressions of $\ln \mathrm{ECe}$ on $\ln \mathrm{EM}_{\mathrm{H}}$ and on the $\ln \mathrm{EM}_{\mathrm{H}}-\ln$ $\mathrm{EM}_{\mathrm{V}}$ difference (following Lesch et al. 1992). Similar equations were obtained using the one-fourth power-transformed variables (following Rhoades et al. 1989). However, none of these models significantly improved the results obtained using the simple linear regressions. So, we used the simpler interpolation for delineating and mapping the salinity of the studied plot.

\section{Soil salinity maps}

Two soil salinity maps (Figure 5) were drawn based on the average ECe profiles for the $0-100 \mathrm{~cm}(\mathrm{~A})$ and $0-150 \mathrm{~cm}$ (B) soil depths obtained from the salinity values measured at the 22 soil sampling points. Two additional maps were based on these measured ECe profiles plus the estimated ECe profiles for the 0-100 $\mathrm{cm}(\mathrm{C})$ and $0-150$ $\mathrm{cm}$ (D) soil depths obtained from the remaining 119 EM38 reading points using calibration equations 7 and 12 (Table 2), respectively. The $0-100 \mathrm{~cm}$ profile is relevant for assessing crop response or development of the natural vegetation, whereas the $0-150$ $\mathrm{cm}$ profile is relevant for assessing the stock of salts in the soil and designing reclamation measures.

The maps of measured ECe (A and B in Figure 5) were similar, and agree with the low variability in vertical soil salinity shown in Figure 4. The only significant difference in these maps is that salinity values $>12 \mathrm{dS} \mathrm{m}^{-1}$ covered a larger area in the $0-100 \mathrm{~cm}$ map than in the $0-150 \mathrm{~cm}$ map (i.e., the $14 \mathrm{dS} \mathrm{m}^{-1}$ contour line was not present in the 0 $150 \mathrm{~cm}$ map). Both maps show that the south half of the plot was non-saline (i.e., ECe $<$ $2 \mathrm{dS} \mathrm{m}^{-1}$ in the area above $140 \mathrm{~m}$ in the longitudinal direction) or slightly saline (i.e., $\mathrm{ECe}<4 \mathrm{dS} \mathrm{m}^{-1}$ in the area between $100 \mathrm{~m}$ and $140 \mathrm{~m}$ ), and that there was a sharp 
transition zone from this low-saline area to the saline area in the north end of the plot. This salinity pattern is in agreement with the unsymmetrical bimodal distributions of the EM38 readings previously presented in Figure 2.

Also, the distribution of the growth of the olive trees planted in the plot agreed with this salinity distribution. Thus, the one-year (1999 to 2000) growth in trunk diameter of the olive trees was $>2 \mathrm{~cm} \mathrm{yr}^{-1}$ for the area of low salinity (i.e., area beyond $100 \mathrm{~m}$ in Figure 6), whereas in the highly saline area (i.e., 0-100 $\mathrm{m}$ of the left corner of the plot in Figure 6) most trees had grown very little or were already dead. In fact, of the 341 trees planted in 1997,173 trees were dead in 1999, increasing to 187 dead trees in 2000 .

The ECe-estimated contour maps ( $\mathrm{C}$ and $\mathrm{D}$ in Figure 5) were quite similar to each other, while closely resembling the previous ECe-measured contour maps (A and B in Figure 5). The similarity of these maps is objectively tested later (Table 3). As expected, the introduction of the 119 ECe estimates significantly improved map detail, so that the contour lines had a smoother appearance, and some patches with ECe values above $2 \mathrm{dS}$ $\mathrm{m}^{-1}$ were found in an area previously classified as non-saline on the basis of the ECemeasured maps. Obviously, the similarity of the ECe-measured and the ECe-estimated maps was due to the high soil sampling density performed in this study. It should be emphasized that using classical soil survey methodology, this sample density would be orders of magnitude lower, and the EM38 maps would then greatly improve the delineation of the spatial variability of soil salinity.

The surface areas within the different salinity intervals in Figure 5 were in general similar for A-D (Table 3). However, (i) the non-saline area (i.e., ECe $<2 \mathrm{dS} \mathrm{m}^{-1}$ ) was around $54 \%$ of the total area in the ECe-measured maps, and decreased to values of $37 \%(0-100 \mathrm{~cm})$ and $49 \%(0-150 \mathrm{~cm})$ in the ECe-estimated maps, (ii) the areas in the $2-$ $4 \mathrm{dS} \mathrm{m}^{-1}$ interval were greater in the estimated than in the measured ECe maps, and (iii) the areas for ECe $>12 \mathrm{dS} \mathrm{m}^{-1}$ were negligible in the ECe-estimated maps, whereas they were around $4 \%(0-150 \mathrm{~cm})$ and $6 \%(0-100 \mathrm{~cm})$ of the total area in the ECe-measured maps (Table 3). In any case, the surface-weighted average ECe values were almost identical in the four maps (i.e., ECe interval from $3.9 \mathrm{dS} \mathrm{m}^{-1}$ to $4.2 \mathrm{dS} \mathrm{m}^{-1}$ ), indicating that the proposed methodology gave similar and consistent values of soil salinity in the studied plot. 


\section{ACKNOWLEDGEMENTS}

This article is a result of the project RTA01-001, funded by INIA (Ministry of Science and Technology of Spain). The second author was granted by Fundación Cándido Iturriaga - María Dañobeitia. 


\section{REFERENCES}

Aragüés R 1987. El sensor electromagnético como método de medida "in-situ" de la salinidad del suelo. Riegos y Drenajes XXI 17, 32-3.

Aragüés R Royo A \& Faci J 1992. Evaluation of a triple line source sprinkler system for salinity crop production studies. Soil Science Society of America Journal 56, 377-383. Aragüés R Playán E Ortiz R \& Royo A 1999. A new drip-injection irrigation system (DIS) for crop salt tolerance evaluation. Soil Science Society of America Journal 63, 1397-1404.

Ba AA 2001. Cartografía y seguimiento de la salinidad de suelos en regadío mediante sensor electromagnético EM38. M. Sc. Thesis. Mediterranean Agronomic Institute. Zaragoza. Spain.

Bercero A \& Aragüés R 1996. Respuesta de la cebada Alpha a la salinidad del suelo. Riegos y Drenajes XXI 88, 45-50.

Herrero J \& Aragüés R 1988. Suelos afectados por salinidad en Aragón. Surcos de Aragón 9, 5-8.

Herrero J \& Bercero A 1991. La salinidad en el nuevo regadío de Quinto (Zaragoza). Suelo y Planta 1, 585-602.

Issaks A \& Srivastava RM 1989. An introduction into applied geostatistics. Oxford University Press, New York.

Lesch SM Rhoades JD Lund LJ \& Corwin DL 1992. Mapping soil salinity using calibrated electromagnetic measurements. Soil Science Society of America Journal 56, 540-548.

Lesch SM Herrero J \& Rhoades JD 1998. Testing for changes in field salinity levels over time using electromagnetic induction techniques. Soil Science Society of America Journal 62, 232-242.

López-Bruna D \& Herrero J 1996. El comportamiento del sensor electromagnético y su calibración frente a la salinidad edáfica. Agronomie 16, 95-105.

Nogués J Herrero J Rodríguez-Ochoa R \& Boixadera J 2000. Land evaluation in a saltaffected irrigated district using an index of productive potential. Environmental Management 25, 143-152.

Rhoades JD Lesch SM Shouse PJ \& Alves WJ 1989. New calibrations for determining soil electrical conductivity-depth relations from electromagnetic measurements. Soil Science Society of America Journal 53, 74-79. 
Rhoades JD Chanduvi F \& Lesch SM 1999. Soil salinity assessment. Methods and interpretation of electrical conductivity measurements. FAO Irrigation and Drainage Paper 57. FAO, Rome.

Soil Survey Staff 1999. Soil Taxonomy. A basic system of soil classification for making and interpreting soil surveys. $2^{\text {nd }}$ Edition. USDA Natural Resources Conservation Service Agricultural Handbook 436. Washington DC.

Tedeschi A Beltrán A \& Aragüés R 2001. Irrigation management and hydrosalinity balance in a semi-arid area in the middle Ebro river basin (Spain). Agricultural Water Management 49, 31-50.

United States Salinity Laboratory Staff 1954. Diagnosis and improvement of saline and alkali soils, ed. LA Richards, Agriculture Handbook 60. USDA. Reprinted 1969. Vizcayno C García-González MT Gutiérrez M \& Rodríguez-Ochoa R 1995.

Mineralogical, chemical and morphological features of salt accumulations in the Flumen-Monegros district. Geoderma 68, 193-210. 
Table 1. Relevant statistics of the EM38 $\left(\mathrm{EM}_{\mathrm{H}}\right.$ and $\left.\mathrm{EM}_{\mathrm{V}}, \mathrm{dS} \mathrm{m}^{-1}\right)$ and the ECe $\left.(\mathrm{dS} \mathrm{m})^{-1}\right)$ values measured for the 141 EM38 points and the 22 soil sampling points.

\begin{tabular}{|c|c|c|c|c|c|c|}
\hline & \multicolumn{4}{|c|}{ EM38 values at the: } & \multirow{2}{*}{\multicolumn{2}{|c|}{$\begin{array}{c}\text { ECe values at the } 22 \text { sampling } \\
\text { points }\end{array}$}} \\
\hline & \multicolumn{2}{|c|}{141 points } & \multicolumn{2}{|c|}{22 sampling points } & & \\
\hline & $\mathrm{EM}_{\mathrm{H}}$ & $E M_{V}$ & $\mathrm{EM}_{\mathrm{H}}$ & $\mathrm{EM}_{\mathrm{V}}$ & $0-100 \mathrm{~cm}$ & $0-150 \mathrm{~cm}$ \\
\hline Mean & 0.87 & 0.92 & 0.96 & 1.01 & 4.94 & 4.76 \\
\hline Median & 0.49 & 0.51 & 0.59 & 0.68 & 2.36 & 2.45 \\
\hline Minimum & 0.33 & 0.36 & 0.27 & 0.29 & 0.77 & 0.72 \\
\hline Maximum & 2.50 & 2.34 & 2.89 & 2.67 & 15.1 & 13.1 \\
\hline Standard deviation & 0.62 & 0.63 & 0.78 & 0.75 & 4.71 & 4.40 \\
\hline Coefficient of variation $\%$ & 71 & 69 & 81 & 74 & 95 & 92 \\
\hline
\end{tabular}


Table 2. Simple linear regressions of $\mathrm{ECe}\left(\mathrm{dS} \mathrm{m}^{-1}\right)$ on $\mathrm{EM}_{\mathrm{H}}$ and on $\mathrm{EM}_{\mathrm{V}}(\mathrm{ECe}=\mathrm{a}+\mathrm{b}$ EM38) obtained for six average ECe soil depths measured at 22 sampling points.

\begin{tabular}{|c|c|c|c|c|c|}
\hline $\begin{array}{c}\text { Computed } \\
\text { sampling depth } \\
\text { (cm) }\end{array}$ & $\begin{array}{l}\text { EM38 } \\
\text { readings }\end{array}$ & $\begin{array}{l}\text { Intercept } \\
\text { (a) }\end{array}$ & $\begin{array}{l}\text { Slope } \\
\text { (b) }\end{array}$ & $\begin{array}{l}\mathrm{R}^{2} \\
(\%)\end{array}$ & Eq. \\
\hline \multirow{2}{*}{$0-25$} & $\mathrm{EM}_{\mathrm{H}}$ & -0.67 & 7.10 & 74.0 & 1 \\
\hline & $\mathrm{EM}_{\mathrm{V}}$ & -1.20 & 7.27 & 71.2 & 2 \\
\hline \multirow{2}{*}{$0-50$} & $\mathrm{EM}_{\mathrm{H}}$ & -0.49 & 6.15 & 81.3 & 3 \\
\hline & $\mathrm{EM}_{\mathrm{V}}$ & -0.94 & 6.29 & 78.0 & 4 \\
\hline \multirow{2}{*}{$0-75$} & $\mathrm{EM}_{\mathrm{H}}$ & -0.46 & 5.78 & 84.6 & 5 \\
\hline & $\mathrm{EM}_{\mathrm{V}}$ & -0.88 & 5.91 & 81.1 & 6 \\
\hline \multirow{2}{*}{$0-100$} & $\mathrm{EM}_{\mathrm{H}}$ & -0.42 & 5.57 & 85.9 & 7 \\
\hline & $\mathrm{EM}_{\mathrm{V}}$ & -0.87 & 5.74 & 83.7 & 8 \\
\hline \multirow{2}{*}{$0-125$} & $\mathrm{EM}_{\mathrm{H}}$ & -0.36 & 5.35 & 85.3 & 9 \\
\hline & $\mathrm{EM}_{\mathrm{V}}$ & -0.84 & 5.56 & 84.5 & 10 \\
\hline \multirow{2}{*}{$0-150$} & $\mathrm{EM}_{\mathrm{H}}$ & 0.23 & 5.19 & 85.3 & 11 \\
\hline & $\mathrm{EM}_{\mathrm{V}}$ & -0.74 & 5.44 & 86.0 & 12 \\
\hline
\end{tabular}


Table 3. Surface areas in each of the ECe intervals given in the first column, obtained by planimetry of the contour maps depicted in Figure 5.

Measured ECe in 22 soil sampling

Measured ECe in 22 soil sampling points plus estimated ECe in 119

ECe interval points; average for depths of: $\quad$ EM38 reading points; average for $\left(\mathrm{dS} \mathrm{m} \mathrm{m}^{-1}\right)$ depths of:

\begin{tabular}{|c|c|c|c|c|c|c|c|c|}
\hline \multirow[t]{2}{*}{$\left(\mathrm{dS} \mathrm{m} \mathrm{m}^{-1}\right)$} & \multicolumn{2}{|c|}{$\begin{array}{c}0-100 \mathrm{~cm} \text { (Fig. } \\
5 \mathrm{~A})\end{array}$} & \multicolumn{2}{|c|}{$\begin{array}{l}0-150 \mathrm{~cm} \text { (Fig. } \\
5 \mathrm{~B})\end{array}$} & \multicolumn{2}{|c|}{$\begin{array}{l}0-100 \mathrm{~cm} \text { (Fig. } \\
5 \mathrm{C})\end{array}$} & \multicolumn{2}{|c|}{$\begin{array}{c}0-150 \mathrm{~cm} \text { (Fig } \\
5 \mathrm{D})\end{array}$} \\
\hline & $\mathrm{m}^{2}$ & $\%$ & $\mathrm{~m}^{2}$ & $\%$ & $\mathrm{~m}^{2}$ & $\%$ & $\mathrm{~m}^{2}$ & $\%$ \\
\hline $0-2$ & 4642 & 54.4 & 4576 & 53.6 & 3143 & 36.8 & 4195 & 49.1 \\
\hline $2-4$ & 971 & 11.4 & 970 & 11.4 & 2538 & 29.7 & 1379 & 16.2 \\
\hline $4-6$ & 445 & 5.2 & 485 & 5.7 & 472 & 5.5 & 537 & 6.3 \\
\hline $6-8$ & 385 & 4.5 & 438 & 5.1 & 527 & 6.2 & 575 & 6.7 \\
\hline $8-10$ & 685 & 8.0 & 808 & 9.5 & 1056 & 12.4 & 1044 & 12.2 \\
\hline $10-12$ & 744 & 8.7 & 946 & 11.1 & 685 & 8.0 & 781 & 9.1 \\
\hline $12-14$ & 528 & 6.2 & 313 & 3.7 & 113 & 1.3 & 25 & 0.3 \\
\hline $14-16$ & 136 & 1.6 & 0 & 0.0 & 1 & 0.0 & 0 & 0.0 \\
\hline$>16$ & 0 & 0.0 & 0 & 0.0 & 0 & 0.0 & 0 & 0.0 \\
\hline Surface-weighted ECe & & & & & & & & \\
\hline
\end{tabular}




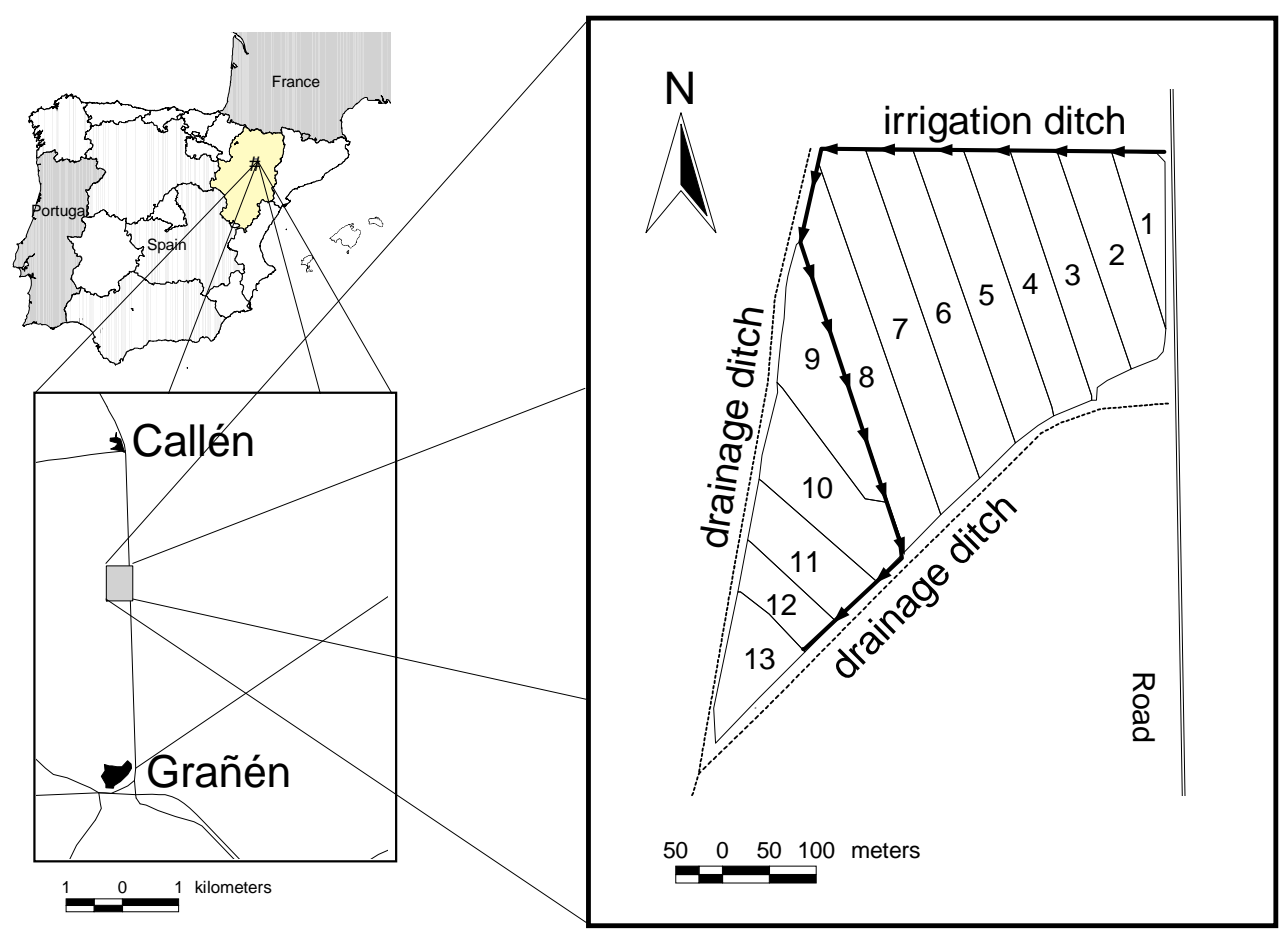

Figure 1. Location of the Callén farm and the plot number 6 under study. 

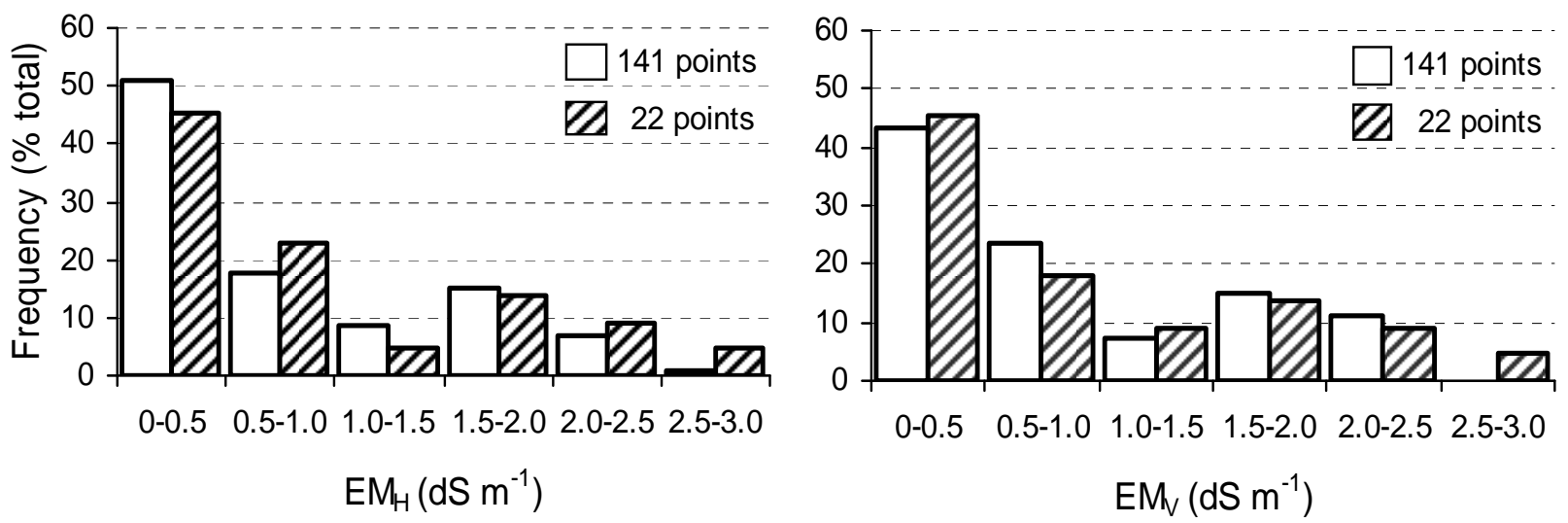

Figure 2. Frequency histograms of the $\mathrm{EM}_{\mathrm{H}}$ (horizontal dipole configuration) and $\mathrm{EM}_{\mathrm{V}}$ (vertical dipole configuration) readings taken in the plot at all the EM38 monitoring points (141) and from soil sampling points (22).
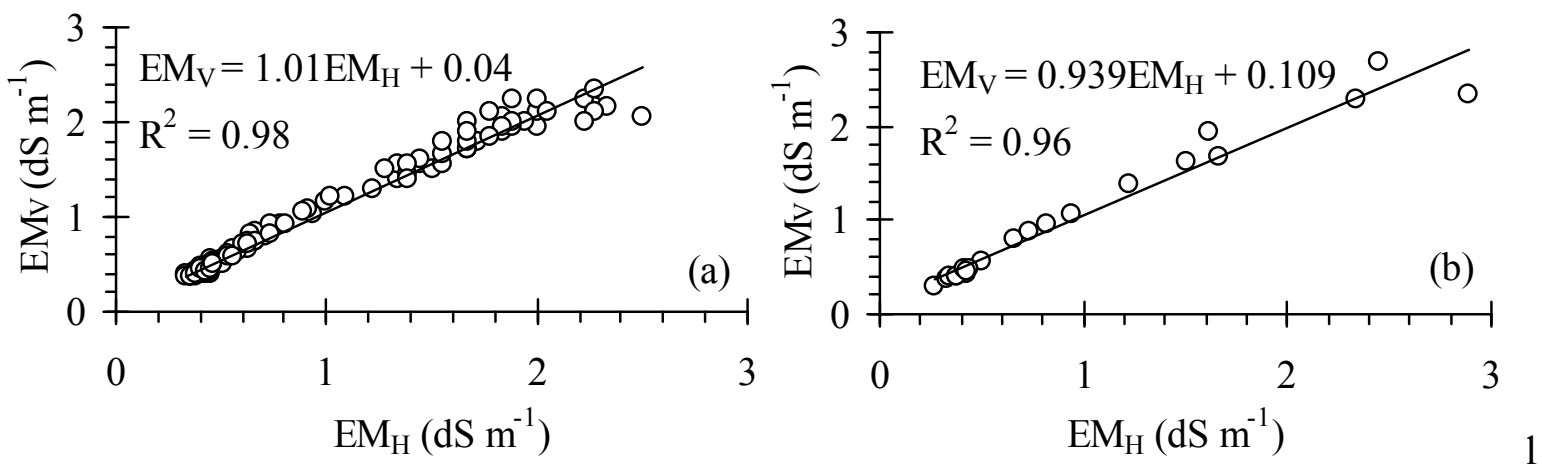

EM38 points and (b) the 22 soil sampling points. 


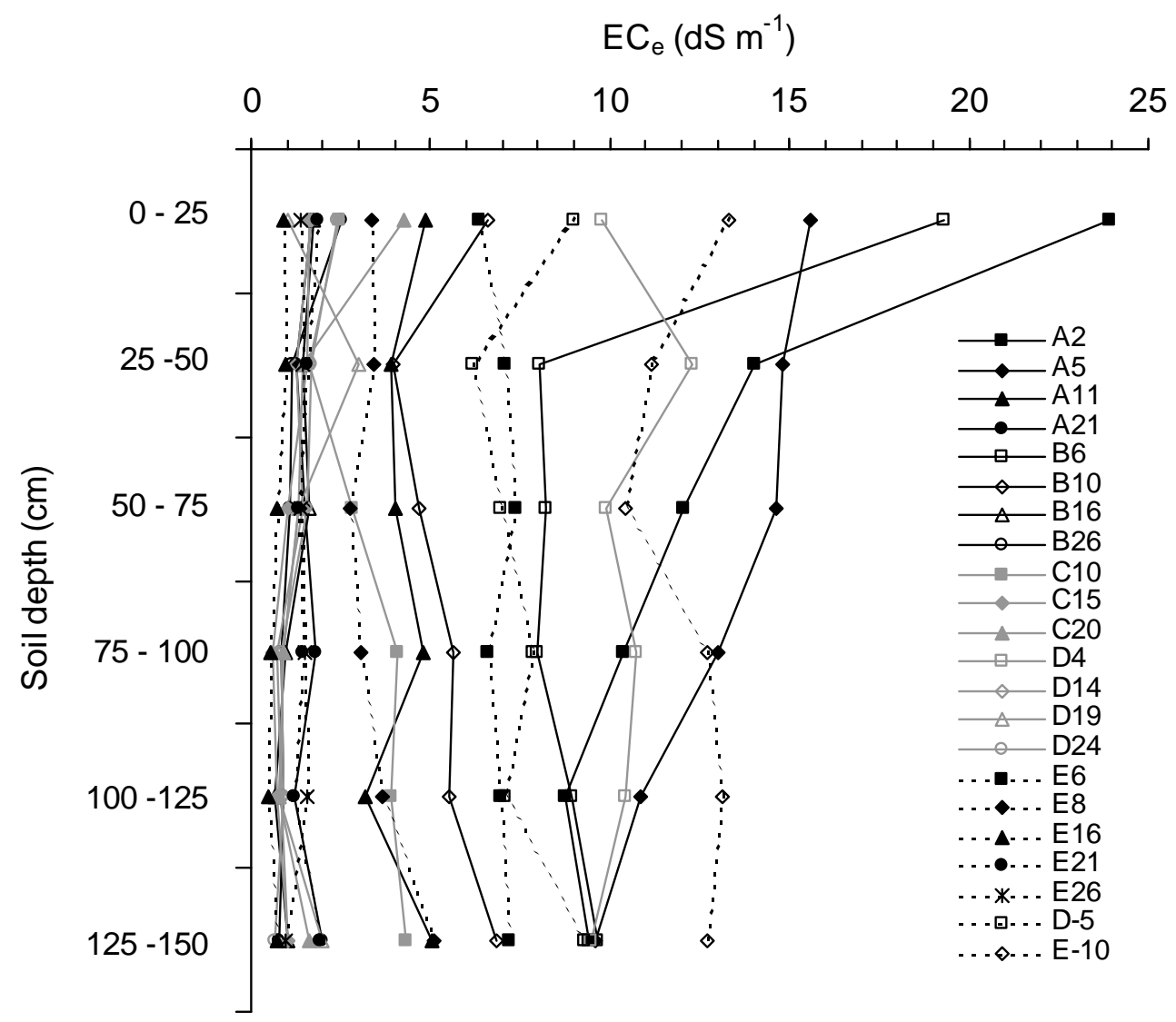

Figure 4. Salinity $\left(\mathrm{ECe}, \mathrm{dS} \mathrm{m}{ }^{-1}\right)$ profiles $(0-150 \mathrm{~cm})$ of the 22 soil sampling points. 


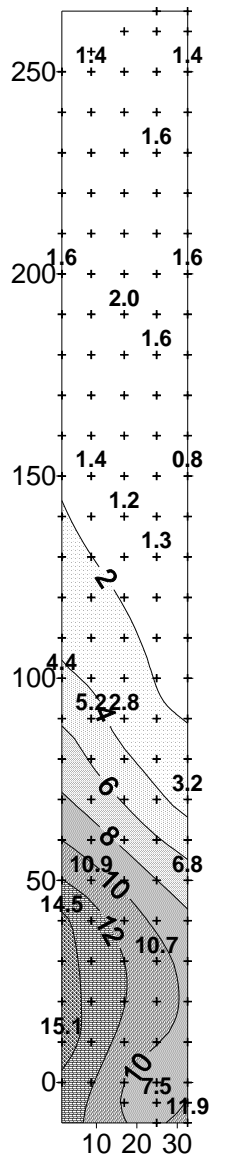

(A)

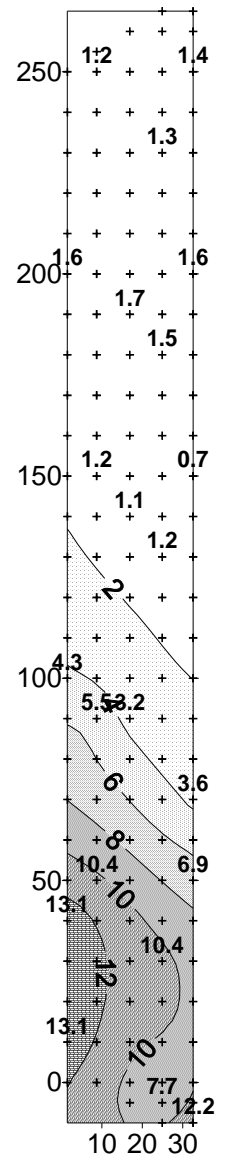

(B)

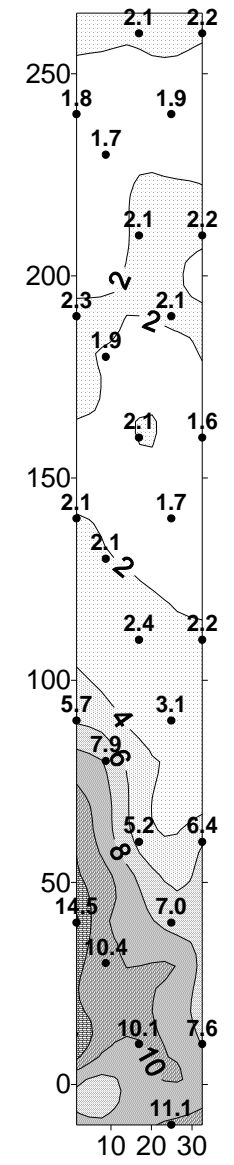

(C)

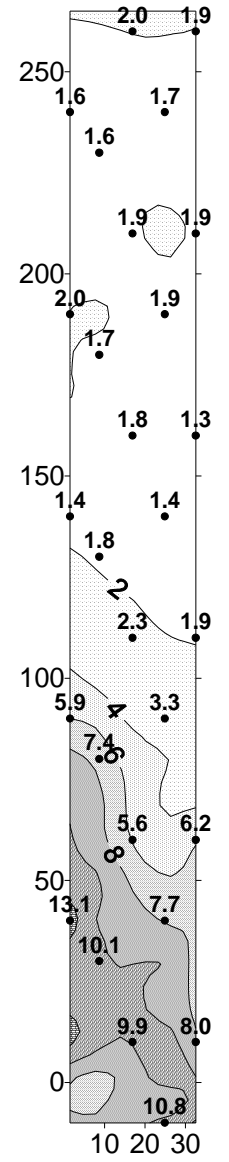

(D)

Figure 5. ECe contour maps of plot number 6 obtained from the measured ECe values at the 22 soil sampling points [average ECe of the $0-100 \mathrm{~cm}(\mathrm{~A})$ and $0-150 \mathrm{~cm}(\mathrm{~B})$ profiles] and from these values plus those estimated for the remaining 119 EM38 measurement points [average ECe of the $0-100 \mathrm{~cm}(\mathrm{C})$ and $0-150 \mathrm{~cm}$ (D) profiles]. The top end of the four maps correspond to the south of the plot. 


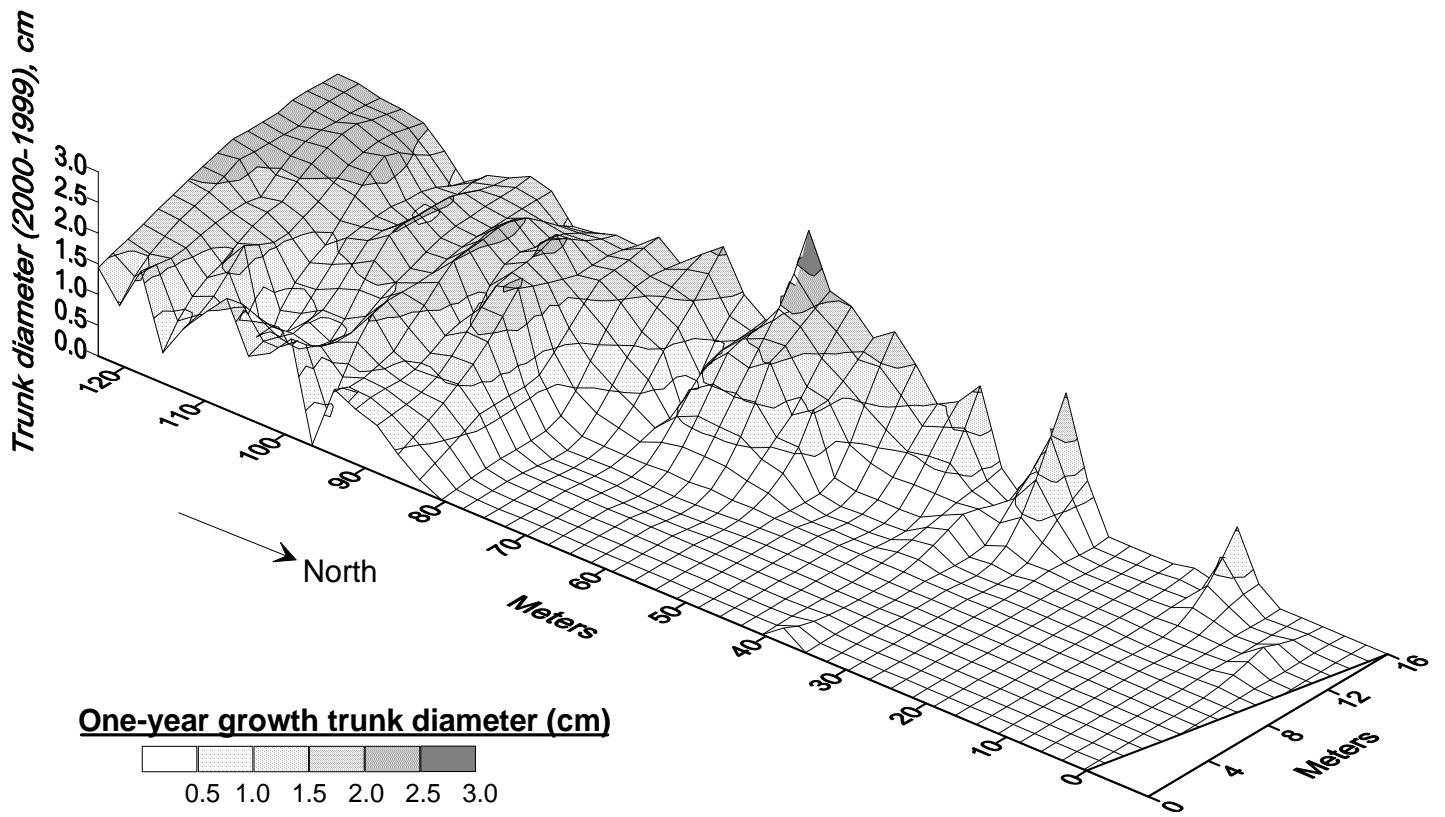

Figure 6. One-year trunk diameter growth of the olive trees planted in 1997 in an area comprising the first $130 \mathrm{~m} \times 16 \mathrm{~m}$ of the studied plot. 


\section{TABLE AND FIGURE CAPTIONS}

Table 1. Relevant statistics of the EM38 $\left(\mathrm{EM}_{\mathrm{H}}\right.$ and $\left.\mathrm{EM}_{\mathrm{V}}, \mathrm{dS} \mathrm{m}{ }^{-1}\right)$ and the ECe $\left(\mathrm{dS} \mathrm{m}^{-1}\right)$ values measured for the 141 EM38 points and the 22 soil sampling points.

Table 2. Simple linear regressions of $\mathrm{ECe}\left(\mathrm{dS} \mathrm{m}^{-1}\right)$ on $\mathrm{EM}_{\mathrm{H}}$ and on $\mathrm{EM}_{\mathrm{V}}(\mathrm{ECe}=\mathrm{a}+\mathrm{b}$ EM38) obtained for six average ECe soil depths measured at 22 sampling points.

Table 3. Surface areas in each of the ECe intervals given in the first column, obtainedby planimetry of the contour maps depicted in Figure 5.

Figure 1. Location of the Callén farm and the plot number 6 under study.

Figure 2. Frequency histograms of the $\mathrm{EM}_{\mathrm{H}}$ (horizontal dipole configuration) and $\mathrm{EM}_{\mathrm{V}}$ (vertical dipole configuration) readings taken in the plot at all the EM38 monitoring points (141) and from soil sampling points (22).

Figure 3. Linear regression equations between $\mathrm{EM}_{\mathrm{H}}$ and $\mathrm{EM}_{\mathrm{V}}$ obtained for (a) the 141 EM38 points and (b) the 22 soil sampling points.

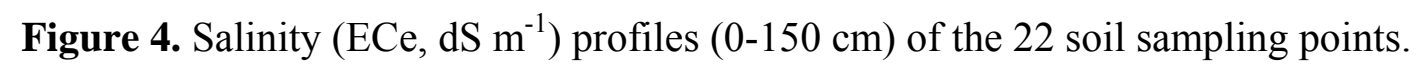

Figure 5. ECe contour maps of plot number 6 obtained from the measured ECe values at the 22 soil sampling points [average ECe of the $0-100 \mathrm{~cm}(\mathrm{~A})$ and $0-150 \mathrm{~cm}$ (B) profiles] and from these values plus those estimated for the remaining 119 EM38 measurement points [average ECe of the $0-100 \mathrm{~cm}(\mathrm{C})$ and $0-150 \mathrm{~cm}(\mathrm{D})$ profiles]. The top end of the four maps correspond to the south of the plot.

Figure 6. One-year trunk diameter growth of the olive trees planted in 1997 in an area comprising the first $130 \mathrm{~m} \times 16 \mathrm{~m}$ of the studied plot. 